\title{
VIAJES DE ILDEFONSO A. BERMEJO POR SUDAMÉRICA EN LA PRENSA PERIÓDICA DEL SIGLO XIX
}

\author{
Diego Chozas Ruiz-Belloso \\ Universidad Federal de la Integración Latinoamericana, Brasil
}

\section{RESUMEN}

A partir de 1862, tras regresar de su estancia de siete años en Paraguay, Ildefonso Antonio Bermejo emprende algunos proyectos con la intención de dedicarse profesionalmente a la escritura de viajes, logrando publicar algunas de sus producciones en importantes revistas españolas de la época. Con el fin de aumentar el atractivo de sus artículos, Bermejo adopta una escritura eminentemente narrativa y, además de basarse en sus vivencias americanas, no deja de recurrir a la imaginación y al plagio. Por otro lado, en sus líneas más personales, Bermejo muestra una postura respetuosa con los nativos bastante inusual en la literatura de viaje del siglo XIX.

Palabras clave: Ildefonso A. Bermejo, literatura de viaje, Paraguay, prensa periódica del siglo XIX.

\section{ILDEFONSO A. BERMEJO'S TRAVEL WRITINGS: \\ GLIMPSES OF SOUTH AMERICA IN 19TH CENTURY SPANISH MAGAZINES}

\section{Abstract}

After his seven-year stay in Paraguay (1855-1862), the Spanish intellectual Ildefonso Antonio Bermejo planned to become a professional travel writer, and he managed to publish some of his productions in important Spanish magazines. In order to increase the attractiveness of his articles, Bermejo adopts an eminently narrative writing, besides fictional stories and plagiarism. On the other hand, in his most personal lines, Bermejo shows a respectful attitude towards natives which is far unusual in the nineteenth-century travel literature.

KeYwords: Ildefonso A. Bermejo, travel literature, Paraguay, 19th-Century periodical press. 
Frente a su limitada repercusión en las letras españolas ${ }^{1}$, Ildefonso Antonio Bermejo (Cádiz, 1820-Madrid, 1892) es una figura recurrente y controvertida en la historiografía de la literatura del Paraguay, país en el que residió durante siete años (1855-1862) realizando una formidable labor cultural. Nadie le niega su papel crucial en los orígenes de la prensa y del teatro paraguayos ${ }^{2}$, pero, por otra parte, el tono satírico del libro de viajes que publicó en Madrid en 1873, Repúblicas Americanas. Episodios de la vida privada, política y social en la República del Paraguay, provocó encendidas e indignadas reacciones durante mucho tiempo. Buena prueba de esto es el furibundo libelo Ildefonso Bermejo, falsario, impostor y plagiario, que Juan O'Leary publicó en 1953, mostrándonos que, ochenta años después de la publicación de Bermejo, la polémica sobre su libro aún no estaba del todo cerrada.

En la primera parte del título del referido libro de viajes, Repúblicas Americanas, viene implícita la intención de que esta obra sea la primera de una serie dedicada a varios países americanos, lo cual viene a confirmarse tanto por las palabras del prefacio que dicen: «Emprendo la historia de mis viajes por la América del Sud» (Bermejo 1873: 3) como por la reseńa (sin firma) que le dedicó La Época el 24 de agosto de 1873, en la que se comenta:

En breve se publicará otro tomo, que tratará de la república de Venezuela, y luego se verán otros hablando de las demás repúblicas; pues el Sr. Bermejo se propone reunir todos los apuntes que tomó en sus largas escursiones por el continente americano.

El hecho de que estos tomos posteriores no salieran finalmente a la luz, truncándose, por tanto, el proyecto de las "Repúblicas Americanas», puede tal vez entenderse como un indicio indirecto de la tibia recepción que este libro sobre Paraguay tuvo en España ${ }^{3}$. Lo cierto es que, aunque este libro de viajes pretendía en principio

${ }^{1}$ Enrique Tierno Galván (1979) señaló que la obra más influyente de Ildefonso A. Bermejo fue la historiográfica, en particular sus libros La estafeta de Palacio y La Historia de la interioridad y Guerra Civil en España, referencias constantes para la historia del siglo XIX que dejaron evidentes huellas en novelistas como Galdós. En lo que se refiere a la principal ocupación literaria de Bermejo, que fue la escritura de comedias, Worth Banner (1951: 106), tras examinar veinticinco de sus piezas, concluye que «en la escuela dramática del siglo XIx Bermejo queda muy cerca de la última fila», de manera que el estudio de Bermejo como autor dramático no se justifica por su calidad u originalidad, sino apenas con el propósito de construir un panorama completo y profundo del teatro espańol de la segunda mitad del siglo XIX.

2 Worth Banner (1951: 105) apunta «la existencia de ciertas evidencias que indican como posible que [Un paraguayo leal] haya sido la primera comedia formal escrita para la escena paraguaya y producida en ella", por mucho que el propio crítico revele que esta pieza de 1858 es un autoplagio de El poder de un falso amigo, escrita por el propio Bermejo en 1849. Además, Bermejo contribuyó decisivamente a la fundación del Teatro Nacional y a las primeras representaciones. En relación con la labor periodística de Bermejo en Paraguay, véase Peiró Barco (2000).

${ }_{3}$ Otra prueba en el mismo sentido sería la escasa atención que la obra recibió en la prensa en el tiempo de su publicación: empleando las herramientas de búsqueda proporcionadas por la Biblioteca Virtual de Prensa Histórica y por la Hemeroteca Digital de la Biblioteca Nacional de Espańa, tan solo hemos encontrado dos breves reseńas sobre el libro de viajes de Bermejo. Una es la ya mencionada que publicó La Época el 24.08.1873. La otra salió a la luz en La Discusión el 08.07.1873. Se 
divertir y asombrar a los lectores españoles, acabó teniendo una repercusión mucho mayor en América del Sur, donde se ha reeditado al menos cuatro veces hasta la actualidad $^{4}$. Este dato es de por sí significativo del importante impacto que la visión externa de los viajeros puede causar en las poblaciones que se describen.

En los Episodios de la vida privada, política y social en la República del Paraguay, Bermejo relata en clave de humor su estancia en la república sudamericana entre 1855 y 1862, adonde fue invitado por Francisco Solano López, hijo del presidente de la República y entonces ministro plenipotenciario del Paraguay en París, ciudad en la que Solano López y Bermejo se conocieron.

Resumidamente, los Episodios de Bermejo, además del intento de ganarse al público español con cuadros chocantes y pintorescos de un país muy poco conocido, pueden entenderse como un tardío desquite personal del intelectual español contra el presidente Carlos Antonio López, al que se dedican la mayoría de los capítulos para, directa o indirectamente, ridiculizarlo y denigrarlo, trazando el retrato de un ser atrabiliario, cruel y despótico, que maltrata a sus ministros (caps. II y XIV) y no duda en sentenciar a muerte a quien grite en público alguna consigna contra él (cap. viI), o incluso a quien rasgue un documento oficial que contenga la firma del presidente (cap. Xv).

No está de más anotar que este libro se abre con un significativo grabado, justo antes de la portadilla, en el que se muestra a un hombre blanco, con sombrero de ala ancha, remangándose un brazo con la intención de azotar con una especie de fusta a un hombre negro, con el torso desnudo, atado a un poste o picota. La leyenda del grabado dice: "Castigo impuesto a un mulato por el presidente de la República», enunciado ambiguo que puede dar a entender que es el propio Carlos Antonio López quien empuña el látigo en la imagen, pero que, en cualquier caso, no quiere dejar lugar a dudas sobre la ferocidad del presidente.

En el capítulo vi del libro, titulado «El azotado», se cuenta que un juez ordenó castigar con cincuenta azotes a un mulato por contrabandear tabaco, mencionándose apenas que al presidente le agradaban este tipo de sentencias, lo cual arroja aún más sombras sobre las intenciones del grabado, que parece proponerse como un resumen visual del libro.

En segundo plano, además de dibujar esa temible caricatura del presidente, el libro ridiculiza a la alta sociedad de Asunción y condena al sucesor presidencial, Francisco Solano López, como belicoso responsable de la destrucción de

trata de una breve y positiva reseña al libro de Bermejo que me ocupa, calificándolo de «librito [...] ameno e instructivo", y considerando lo cómico y casi inverosímil de la obra como reflejo de la realidad de un país "no bien conquistado para la civilización", achacando esta situación el reseńista al despotismo que ha regido el país desde su independencia. El reseñista, además, refuerza el viejo estereotipo sobre los nativos hablando del «natural perezoso de los indios guaranís».

${ }^{4}$ Aparecieron dos ediciones en Asunción (Librería y Papelería Nacional, 1908, y Quell y Garrón, 1913) y una tercera en Buenos Aires con el título de Vida paraguaya en tiempos del viejo López (Eudeba, 1973). Además, la obra fue traducida al portugués de Brasil por Earle D. Macarthy Moreira y publicado por la EdiPUCRS en 2002. 


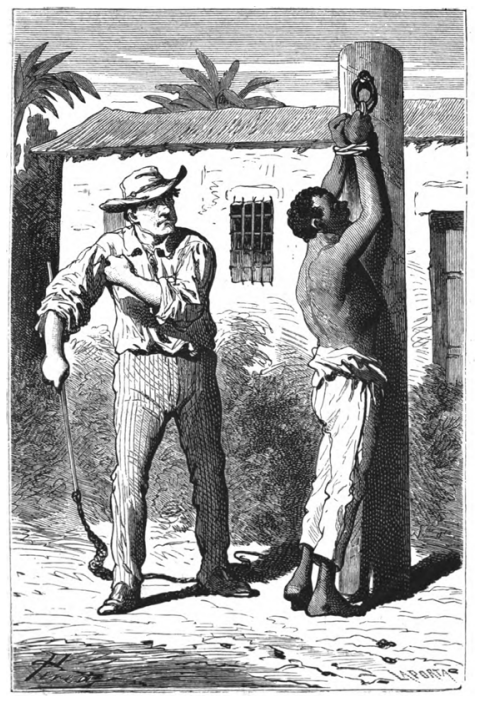

Castigo impuesto a un mulato por el presidente de la República.

Paraguay. Los indígenas del país apenas son tratados muy de pasada en el apretado capítulo XviII, en el que se describe en términos muy peyorativos un funeral indio, tildándolo de esperpéntico y exagerado. Aunque se califica a los indios de «salvajes», en ningún momento el observador se siente amenazado por ellos, reservándose la sensación de peligro y la experiencia de la aventura (indispensables en las narraciones viajeras más exitosas) al viaje a las cercanías de Asunción que se relata en los capítulos viII al XII, en el que la vida de Bermejo estará varias veces en juego debido a la proximidad de extraños y ponzoñosos animales.

Como adelantábamos más arriba, Juan O’Leary denunció con vehemencia en su libro de 1953 las falsedades e inexactitudes contenidas en el libro de viajes de Bermejo, desgranando con minuciosidad todos los casos en los que la ficción y la fantasía malintencionada toman el lugar de la realidad. O'Leary probó además que extensos y numerosos pasajes de los Episodios de Bermejo son un plagio del libro Los intereses católicos en América, obra del religioso chileno José Ignacio Víctor Eyzaguirre. O'Leary critica aun el servilismo ditirámbico que Bermejo exhibió en los medios escritos paraguayos durante su estancia en el país, adulación que, según este crítico, no fue del gusto del nuevo gobernante, Solano López, y acabó siendo el motivo de su caída en desgracia y su regreso a Españas.

5 Esta obra de O'Leary puede leerse completa en la excelente página web de Eduardo Pratt, el Portal Guarani (https://www.portalguarani.com/500__juan_emiliano_oleary/19831_prosa_polemica_1982_ensayos_de_juan_e_oleary.html). 
Los Episodios de la vida privada no fueron la única incursión de Ildefonso A. Bermejo en la literatura de viaje: tras su regreso de Paraguay en 1863, y hasta 1866, publicó cuatro textos de esta naturaleza en importantes revistas españolas de la época ${ }^{6}:$ "Tacuatí. Crónica americana» apareció en El Museo de las Familias en $1863^{7}$; «Escursiones por la América del Sur. Razonamientos de un salvaje» fue publicado en El Museo Universal en el n..$^{\circ} 18$ de 1864; la revista La América publicó los dos restantes: "Constitución, usos y costumbres de los indios peguenches (Chile)» (27/08/1866) y «La negra de Guayaquil» (12 y 27/09/1866), que volvería a ser publicado, incompleto, en El Museo de las Familias en 1868.

«Tacuatí. Crónica americana» es una narración considerablemente extensa que ocupa seis páginas en su primera entrega y tres más en el siguiente número. Antes de dar paso al relato en sí, un preámbulo nos explica que "para apreciar debidamente a estos países» de la zona del Río de la Plata es preciso ignorar las corrientes imitadoras de la cultura europea, así como las corrientes migratorias que llegan de Europa huyendo de la pobreza trayendo consigo lo peor del Viejo Continente. La esencia del lugar estaría en la naturaleza y en los pueblos indígenas, a los que hay que conocer. El narrador nos informa que va a hablar de su contacto personal con los payaguás.

Dice a continuación Bermejo que cierto día (que él sitúa con exactitud en febrero de 1858) paseando a caballo por la ribera del Paraguay, vio una canoa cargada con víveres y bebidas, y al saber de los indios que eran para algún tipo de celebración, el autor dejó su caballo a un mulato desconocido que se bañaba por allí (confiando plenamente que lo llevaría a su casa, lo que en efecto ocurrió) y se juntó a los indios movido por la curiosidad y mostrando un arrojo propio de aventureros. De esta manera, según dice, se interna en el territorio de los indios, en el Gran Chaco, «sin otra defensa que el rebenque de mi caballo», sugiriendo un peligro latente que, no obstante, no llegará a materializarse, pues Bermejo será recibido inmejorablemente en las tolderías, hasta el punto de que el cacique Miguel le cede su hamaca y lo mece en ella hasta que el huésped cae dormido.

En este punto la narración sufre un brusco giro: despierta a Bermejo un inglés para pedirle que traduzca al castellano un manuscrito en guaraní que nadie consigue traducirle correctamente. Bermejo lo hará en nueve días. A continuación, se transcribe el texto traducido, obra de un jesuita, Bernardo Cabrera Fuensaldaña, en el siglo XviII. El jesuita que cuenta la historia habla a su vez de otro padre, llamado Maldonado, que fue de Buenos Aires a Asunción en los tiempos del goberna-

${ }^{6}$ Los cuatro textos forman parte del Corpus de viajes por Latinoamérica en la prensa periódica (1850-1900), producto principal del proyecto de investigación Análisis del discurso de viajeros por Latinoamérica en el siglo xIx: su contribución a las identidades nacionales (Universidad de la Integración Latinoamericana-UNILA).

7 Publicado en dos entregas, ocupa las páginas 258-263 y 267-269 del tomo correspondiente al ańo 1863. Raquel Pérez Valle, en su tesis Literatura y periodismo en el siglo XIX: El Museo de las Familias (1843-1870), pp. 708-711, comenta este texto junto a otro de Bermejo, «La negra de Guayaquil», incluyendo ambos en el grupo de la literatura de viaje. 
dor Fernando Pedreras. Desde los pies de página, el traductor Bermejo cuestiona la exactitud de lo que narra el manuscrito, al no corresponder las descripciones geográficas a lo que él conoce. Este jesuita, Maldonado, cierto día encontró a un niño desesperado junto al cadáver de un hombre joven. El niño habla en una lengua que el religioso no entiende, pero logra comunicarse con gestos curiosamente occidentales: se arranca los cabellos en señal de duelo, se lleva la mano al corazón para demostrar el afecto que sentía por el muerto o besa las manos del jesuita.

El niño es Tacuatí, que recibe una primorosa formación del jesuita, hasta el punto de que, con 22 ańos, mantiene una conversación con el padre en la que cuestiona los grandes principios de la civilización occidental, especialmente el ansia de riquezas, sabiéndose dueño de enormes tierras que le dan todo lo que necesita. Tacuatí, sin embargo, se enamora de la sobrina del gobernador, a la que llega a salvar de una boa constrictor, pero solo se le concederá su mano si consigue mucho oro. El joven revela que sabe dónde conseguirlo a raudales, de manera que el jesuita acaba proponiendo a su discípulo como esposo de la joven a cambio de una importante dote. El gobernador aceptará la boda a cambio de una mina de oro. Tacuatí desaparece durante algunos meses para "preparar» una mina fuera del territorio frecuentado por los indios. El gobernador acepta la boda, pero queriendo descubrir más minas, nombra a Tacuatí adelantado a cargo de 600 soldados para imponerse a los guaraníes. Tacuatí, la joven mujer y el jesuita huyen en canoa y se integran en la vida salvaje. El padre Maldonado convierte al cristianismo a todos los indios que va conociendo, y estos aceptan la venida de más jesuitas. Es nada menos que el origen de las misiones.

El siguiente texto publicado, «Escursiones por la América del Sur. Razonamientos de un salvaje», se nos presenta ya desde su título como perteneciente a una serie de viajes del autor por Sudamérica, serie que, no obstante, por motivos que desconocemos, no tendría continuidad en El Museo Universal.

La primera columna, con función introductoria, es una descripción de la zona del Gran Chaco y de sus pobladores indios, sobre los que se habla con términos elogiosos: nación enérgica, raza valerosa, de elevada estatura, «muy leales en sus contratos, aun con sus propios enemigos. Además de su valor reconocido, se han hecho notables por su inteligencia».

A continuación, irrumpe la primera persona en un párrafo que no tiene desperdicio:

Mi larga residencia en los países que confinan con estos desiertos, mi escesiva curiosidad y los recursos que me suministraba la benevolencia de un gobierno á quien tuve la fortuna de hacerme simpático, me facilitaron en determinados periodos la ocasión de esplorar aquellos terrenos y conocer algunas tribus mansas, pero mi ánimo no quedaba cumplidamente satisfecho si no visitaba esa tribu arrogante, que tan memorable se ha hecho por sus proezas en tiempo de nuestros conquistadores, y que tanto se abstienen de visitar los viajeros por el terror que inspira.

De esta manera, Bermejo se suma a una caravana comercial, emprendiendo un penoso viaje en el que, para empezar, el barco se encalla por doquier, y 
más adelante los viajeros se hunden en pantanos, los matorrales espinosos les rasgan las ropas y la carne, sufren las lluvias y el frío del viento del sur, etc. Por fin, el 6 de junio de 1860, a las nueve y media de la mañana, realizan el primer contacto con estos indios; una avanzadilla de apenas seis individuos entre los que se encuentra el cacique Caracatuí.

A partir de ese momento, el texto se centra en las conversaciones entre Bermejo (al que se ha encomendado la "dirección moral» de la expedición) y el cacique, con la mediación del intérprete Cirilo ${ }^{8}$. El subtítulo de «razonamientos de un salvaje» se refiere justamente a las elocuentes palabras del cacique, llenas de discernimiento y sabiduría, con algún que otro toque de exotismo, que admiraron y despertaron en el autor un enorme respeto. El cacique sintió en todo momento este respeto, esta falta de burla («No he visto en tu rostro un signo de mofa», dice el cacique), y acaba reconociendo que, en principio, los comerciantes estaban condenados a muerte por deseo de lo que transportaban, pero que, por su actitud y sus palabras, el cacique ordenó a los suyos que no los maltrataran.

Bermejo permanecerá nueve días en el lugar, aprovechando la estancia para realizar estudios científicos de la flora, la fauna y los minerales locales. También, en algún momento, montará su equipo fotográfico para retratar al cacique con su mujer y dos hijos, revelando allí mismo una muestra.

El Museo Universal publica en sus páginas un grabado, reproducción de una fotografía de «El cacique Caracatuí, y su hijo», que viene a ser el documento gráfico que certifica la veracidad del relato?.

En estos dos primeros textos apreciamos varios aspectos en común: ambos son textos narrativos en primera persona en los que el narrador-autor se adentra en el Gran Chaco y entra en contacto con nativos, lo cual, presumiblemente, sería muy del gusto del lector occidental; como es habitual en las narrativas viajeras, la acción se sitúa con gran exactitud espaciotemporal, aportando verosimilitud; en ambas narraciones existe una presencia latente del peligro, más pronunciada en «Razonamientos de un salvaje», donde la vida del viajero llega a verse amenazada; en consonancia con lo anterior, el narrador-autor se presenta a sí mismo como un aventurero, siguiendo a rajatabla las características canónicas del explorador, tipo a caballo entre lo histórico y lo literario que gozaba de un extraordinario prestigio social en el siglo xIx; contrariando uno de los rasgos más propios del género «relato de viajes» ${ }^{10}$,

${ }^{8}$ El Archivo Nacional de Asunción guarda un documento que comprueba que Bermejo tuvo un esclavo durante seis años llamado Cirilo Samaniego, al cual alfabetizó y enseńó el oficio de carpintero, devolviéndolo al estado en diciembre de 1860 por haberse dado a la bebida y estar ocasionando desórdenes. (http://historia.anasnc.senatics.gov.py/uploads/r/archivo-nacional-de-asuncion/5/4/54244/PY-ANA-SH-329n16-116-117.pdf).

${ }^{9}$ Sin embargo, por una parte, el grabado reproducido no se corresponde con la fotografía de la familia del cacique de la que habla el texto y, por otro lado, aunque el pie del grabado explica que las figuras retratadas son el cacique y su hijo, la figura infantil de la imagen parece ser la de una niña.

${ }^{10}$ Luis Alburquerque García $(2011,2015)$ parte de Sofía Carrizo Rueda (1997) para desarrollar el concepto de «relato de viajes», género en el que predomina lo descriptivo frente a lo narrativo, lo factual frente a lo ficcional y lo objetivo frente a lo subjetivo. 


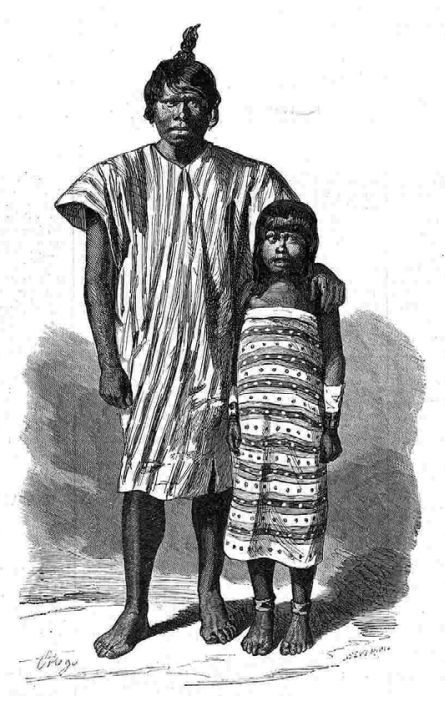

El cacique Caracatuí, y su hijo.

(El grabado es reproducción de una fotografía).

en ambos textos se da prioridad a lo narrativo frente a lo descriptivo, minimizándose la descripción y poniéndola al servicio de la trama; en este sentido, los dos textos adoptan características formales de la narrativa de ficción, como pueden ser la inclusión de diálogos, la dosificación de cierta intriga o la presencia de un desenlace preñado de un mensaje a modo de conclusión o cierre; aunque ambos textos pudieron ser leídos en la época como verídicos, lo cual los sitúa dentro de lo que se entendía en el siglo xIX como literatura de viaje ${ }^{11}$, una lectura crítica adivina en las dos narraciones un importante componente de ficción, una confusión premeditada entre lo factual y lo imaginario que, pensamos, pretendía aportar credibilidad a todos los pasajes ficticios; por último, los dos textos presentan una visión positiva del indígena, algo bastante insólito en la literatura de viaje de su tiempo ${ }^{12}$.

Hay, sin embargo, una inconsistencia importante entre los dos textos: mientras en el viaje de 1858 Bermejo dominaba la lengua guaraní hasta el punto de que lo buscaron para que realizase una traducción al castellano de un texto manuscrito

11 Aunque no hemos encontrado registros de la expresión «literatura de viaje» en el español de la segunda mitad del siglo xix, en su día asumimos esta extendida denominación (Chozas 2014: 120-126) para englobar los variadísimos textos que la prensa periódica de la época publicaba en sus secciones de "Viajes», textos que apenas tenían en común el hecho de ser presentados al público como productos de viajes reales. En este sentido debe entenderse «literatura de viaje» en el presente artículo, concepto en el que no tendrán cabida, por tanto, las narraciones de viajes abierta e inconfundiblemente ficticias.

12 Ibid, pp. 191-207. 
en esa lengua, dos años más tarde, en 1860, Bermejo habrá de valerse de un intérprete para comunicarse con un cacique de la misma zona: el Gran Chaco. Por lo tanto, una de las dos historias es falsa en lo que atañe al conocimiento del guaraní por parte del autor.

En todo caso, ambos textos tienen en común algo importante con otro de los textos mencionados de Bermejo, «La negra de Guayaquil»: la visión respetuosa del nativo y la empatía hacia el otro por parte del viajero, que es también la voz narradora.

Además, «La negra de Guayaquil» comparte con los dos textos anteriores su carácter predominantemente narrativo, hasta el punto de que, aunque ha sido clasificado por la crítica ${ }^{13}$ como literatura de viaje, este texto se apropia tan completamente de las características de la narrativa de ficción, incorporando incluso una conclusión moralizante, que la historia de la negra Dominga Bamboyena pasa a encuadrarse en un terreno ambiguo en el que realidad y fantasía aparecen indiferenciadas.

Se abre el texto con una cita en inglés de Milton ${ }^{14}$ que evidencia las intenciones literarias del autor y cuyo contenido moral enlaza con el último tramo de la narración: la ganancia fácil y perezosa es un consejo del demonio, viene a decirse.

El narrador evita la descripción de Guayaquil alegando que las ciudades bañadas por el Pacífico apenas tienen atractivos para los viajeros, y ya en el tercer párrafo se da paso a la narración en primera persona: «Una mańana, en la que recorría las calles de esta ciudad», etc. ${ }^{15}$.

Huyendo de una lluvia repentina, el narrador se refugia en una librería, que resulta ser propiedad del español exiliado Miguel Campero. Este se muestra abatido y suspira a menudo, y ante las indagaciones del viajero, empezará a explicar que su tristeza se debe a un golpe de mala fortuna que lo privó de ser millonario, y deja entender que todo tiene relación con Dominga Bamboyena, una mujer negra de riqueza fabulosa que es además una lectora empedernida, la mejor clienta de la librería.

En este punto, el narrador declara:

Estas palabras me anunciaban una historia. ¿A quién no le gustan las historias cuando se viaja? A mí más que a nadie, cuya principal ocupación en mis largas expediciones ha sido recoger cuantas historias y anécdotas he podido en los infinitos parajes por donde he transitado.

A partir de entonces se cede la voz narradora al librero, quien relata que, a partir de un momento dado, Dominga Bamboyena comenzó a manifestar mucho interés por él. Campero (junto con el lector) termina descubriendo que Dominga no espera casarse con él, sino pedirle su colaboración en un asunto bastante delicado: Bambo-

13 Ver nota 7.

14 «Thus Belial, with words cloth'd in reasons garb, Counsell'd ignoble ease and peacefull sloth, not peace».

15 Nótese la falta de concreción temporal, cuando una característica de la literatura de viaje suele ser la precisión en la localización espaciotemporal. 
yena obtuvo su riqueza jugando a la ruleta, aplicando un método inventado por su marido, prodigio de las matemáticas, negro liberto, brasileńo como Dominga, que llegó a ser coronel del ejército y recogió su método infalible en un libro manuscrito que su viuda guarda como un tesoro. Dominga necesita ahora la ayuda de alguien de mucha confianza para que juegue por ella, que ya tiene sus facultades mermadas por la edad, y consiga la cantidad necesaria para abrir una institución de caridad y retirarse definitivamente del juego. Campero acepta el trato, que le permitirá cerrar su librería y pasar a vivir de rentas, y comienza a entrenarse en la técnica explicada en el libro hasta altas horas de la noche en casa de Bamboyena.

Sin embargo, días antes de emprender un viaje a Quito para empezar a jugar en los casinos de la ciudad, Campero llega a casa de Bamboyena y se depara con la noticia de que la mujer ha muerto y, lo que es peor, antes de morir ordenó quemar el libro de su marido. Con esta última decisión, Dominga Bamboyena logra redimirse, pero el español Miguel Campero se queda preso para siempre en la melancolía de su ambición frustrada ${ }^{16}$.

La historia termina abruptamente con una condena moral del narrador que despierta la ira del librero, después de lo cual el viajero sale del establecimiento.

Como venimos diciendo, el texto ofrece todas las características del relato de ficción, como son los diálogos, la administración de la intriga o el mensaje moral. En este mismo sentido, extraña que se identifique con nombre y apellidos a un personaje español al que se condena en el texto éticamente, personaje que, además, de ser verídico, aún debería estar vivo en el momento de la publicación del relato. Lo más probable es que el librero sea una invención que facilita narrativamente el acceso al personaje principal, que es la negra Bamboyena. El conjunto de la historia bien pudo ser inspirado por alguna noticia curiosa hallada por Bermejo en la prensa sudamericana que hablaría de un genio de las matemáticas negro que ideó una manera de enriquecerse en los casinos. Por lo demás, tampoco hemos hallado ninguna constancia biográfica de que Ildefonso Bermejo viajara al Ecuador durante su estancia en el claustrofóbico Paraguay descrito en los Episodios de la vida privada.

En cualquier caso, a pesar de la muy probable naturaleza ficticia de todo o de la mayor parte del relato ${ }^{17}$, las ambigüedades del texto nos permiten suponer que muchos lectores de la época pudieron creer en la veracidad de lo narrado.

Por último, y dejando ya de lado el problema de la veracidad, vale la pena destacar aún sobre este texto que la figura de una mujer negra riquísima y amante de las artes y de la literatura supone en el contexto de su época un elemento insólito y a contracorriente, como no lo es menos el personaje del coronel del ejército brasi-

${ }^{16}$ Hay una aparente inconsistencia interna en la historia: Campero se había entrenado a conciencia en el método del libro para no necesitar consultarlo en las casas de juego, de manera que la destrucción de este objeto no implicaba el fracaso del plan original.

17 Encuentro otros dos indicios no conclusivos de que «La negra de Guayaquil» pudo leerse como un relato de ficción: por un lado, el texto ocupa en las dos entregas las páginas de cierre de $L a$ Ámerica, espacio en el que solían publicarse relatos ficticios; por otro lado, en el índice del tomo correspondiente, «La negra de Guayaquil» fue incluida dentro del grupo de «Novelas y artículos recreativos». 
leño, nacido esclavo, dueño de una portentosa habilidad matemática. En un tiempo en el que la cultura occidental, con respaldo científico, asume la existencia de «razas inferiores», entre las que se sitúa la negra, grupo humano que se denigra constantemente desde las publicaciones periódicas, los personajes de Dominga Bamboyena y su marido rompen las expectativas del público, resultan chocantes. Aunque puede argüirse que lo inaudito de estos personajes cumple una función narrativa al atraer la atención del lector, y que Bamboyena y su marido no dejan de presentarse como asombrosas excepciones a la regla, lo cierto es que, en su contexto histórico, este retrato con cualidades positivas de personas negras constituye un caso raro de quiebra de los estereotipos más extendidos en su tiempo.

En el número anterior de La América (del 27/08/1866), Ildefonso Bermejo había publicado "Constitución, usos y costumbres de los indios peguenches (Chile)", de naturaleza muy diferente a los tres comentados hasta el momento: aunque hay varios indicios de que se parte de experiencias personales y se emplea la primera persona del plural, este texto es totalmente descriptivo y está desprovisto de los elementos más característicos de la narración: no hay acontecimientos localizados espaciotemporalmente, no hay personajes ni se mencionan nombres propios, sino que se habla apenas de características generales del pueblo y de sus costumbres como pueden ser el luto, las bodas o los nacimientos, sin citar fuentes documentales para estas informaciones. Además, frente a los textos anteriores, la imagen que se da de los nativos es muy negativa: se habla de la fealdad de las mujeres, de la cobardía de los hombres, de su discurso altisonante, etc. Concluye el texto prometiendo otro artículo similar sobre los mapuches, que no llegó a publicarse en La América.

Buscando más informaciones sobre los peguenches, descubro que el texto de Bermejo es un plagio, con numerosísimas coincidencias literales, de la segunda parte de la obra póstuma del militar chileno Luis de la Cruz (1768-1828), Descripción de la naturaleza de los terrenos que se comprenden en los Andes, poseidos por los peguenches; $y$ los demás espacios hasta el río de Chadileubu, publicado en Buenos Aires en $1835^{18}$.

A pesar de la alta fidelidad de Bermejo a su omitida fuente, el texto de $\mathrm{La}$ América presenta cambios como la supresión de todos los nombres propios y de las experiencias del militar chileno, cuyo texto es más narrativo. Comprime también extensos pasajes en apenas un párrafo. Llama la atención, además, otro cambio significativo: mientras en el original chileno se dice que los peguenches vendían a los niños que capturaban como botín a comerciantes españoles, Bermejo, a la hora de publicar su versión en una revista española, prefirió hablar de compradores europeos.

Existe aún otra obra de Ildefonso Bermejo que podría confundirse, por su título, con literatura de viaje: se trata de la Relación esplicativa acerca de las investigaciones históricas, geográficas y estadisticas hechas en varias repúblicas de la América

18 Accesible en línea en http://www.cervantesvirtual.com/obra-visor/descripcion-de-la-naturaleza-de-los-terrenos-que-se-comprenden-en-los-andes-poseidos-por-los-peguenches-y-los-demasespacios-hasta-el-rio-de-chadileubu--0/html/ff874226-82b1-11df-acc7-002185ce6064_6.html\#I_2_. 
Meridional en el periodo de ocho años ${ }^{19}$, publicada en Madrid en 1864, es decir, poco después del regreso de Bermejo de Paraguay.

No hay, sin embargo, en esta publicación relatos de viajes ni descripciones geográficas. Se trata de un peculiar documento de apenas 25 páginas que comienza con una introducción dirigida a la reina de España en la que Bermejo resume sus actividades en el Paraguay, destacando su defensa de los intereses españoles y de la fe católica durante su estancia en este país, asegurando que su labor contribuyó a mejorar la imagen de España entre los paraguayos. A continuación, la Relación esplicativa recoge algunas cartas y extractos de periódicos que vienen a ser credenciales elogiosas y comprobantes documentales de las labores realizadas por Bermejo en Paraguay. Por último, en un formato idéntico al de los índices de obras geográficas y de viajes, se reúnen los contenidos que Bermejo dice haber estudiado durante "cinco ańos de consecutivas escursiones ${ }^{20}$ y que comprenden variadísimas informaciones sobre el Imperio del Brasil, la República Oriental del Uruguay, la Confederación Argentina y las Pampas de Buenos Aires, y la República de Paraguay. Tras el listado de estos contenidos, una breve nota cierra el documento diciendo: «De todos estos trabajos ha tenido perfecto conocimiento el almirante Pinzón el año de 1863, durante su permanencia en el puerto de Montevideo $»^{21}$, lo que parece dar a entender que los profundos estudios sobre estos países ya están concluidos y prácticamente listos para su publicación.

En la Relación esplicativa no se explicita la motivación de la misma, pero por el pasaje en el que se comenta que Bermejo emprendió estos estudios por propia iniciativa «habiendo observado que varios súbditos de Francia, Inglaterra y Alemania viajaban por aquellos países, por cuenta de sus respectivos gobiernos, o pensionados por corporaciones científicas ${ }^{22}$, podemos colegir que nuestro autor buscaba un patrocinio del gobierno español a posteriori para sus trabajos geográficos. Por otro lado, puesto que Bermejo llevó a imprenta esta Relación esplicativa, es de suponer que imprimiría un número suficiente de ejemplares para distribuirlos entre entidades que podrían financiar su proyecto, como pueden ser sociedades científicas y editoriales.

Ahora bien, tomando la Relación en el contexto de la literatura de viaje de Bermejo que acabamos de analizar, y dado que apenas hay pruebas documentales ${ }^{23}$ de que el autor permaneció durante un tiempo muy breve en Brasil y Argentina en el transcurso de sus viajes de ida y vuelta entre Espańa y Paraguay, cabe suponer que Bermejo pretendía llevar a cabo su gran proyecto basándose no en observaciones de primera mano, sino en obras anteriores que probablemente adquirió en Sudamérica. Asimismo, por lo que sabemos del estilo y las características del autor,

19 Este documento está accesible en línea en la Biblioteca Digital Hispánica de la Biblioteca Nacional de España: http://bdh-rd.bne.es/viewer.vm?id=0000114839\&page=1.

${ }^{20}$ Ibid., p. 11.

${ }^{21}$ Ibid., p. 25.

22 Ibid. pp. 3-4.

${ }^{23}$ Las cartas y artículos periodísticos recogidos en la propia Relación esplicativa. 
previsiblemente sus escritos sobre las naciones sudamericanas vendrían entreverados de narraciones ficticias.

En cualquier caso, Bermejo no obtuvo apoyo para esta ambiciosa obra que habría ocupado varios tomos, con lo que apenas podemos hacer conjeturas de cuál habría sido el resultado a partir de las intenciones apuntadas en el documento y de las características de las obras que de hecho publicó.

Llegados a este punto, es hora de extraer conclusiones acerca de la literatura de viaje que Ildefonso Antonio Bermejo publicó en la prensa periódica:

A su regreso de Paraguay, y muy posiblemente impulsado por necesidades económicas, Bermejo pergeñó la idea de rentabilizar su estancia en la república sudamericana presentándose ante el público español como escritor de viajes, género muy demandado en la época y que llegó a posibilitar la aparición de viajeros profesionales que colaboraban con diversos medios escritos ${ }^{24}$. Al igual que su libro sobre su estancia en Paraguay, los escritos «Escursiones por la América del Sur. Razonamientos de un salvaje» $\mathrm{y}$ «Constitución, usos y costumbres de los indios peguenches (Chile)» se presentan como muestras de series más extensas de textos sobre viajes. La Relación esplicativa que Bermejo publicó al poco de regresar de Paraguay incide en esta intención del autor de dedicarse profesionalmente a la literatura de viajes.

Puesto que El Museo de las Familias, El Museo Universal y La América no eran publicaciones científicas, sino revistas culturales y literarias dirigidas al conjunto del público burgués, Bermejo compuso sus textos pensando en cumplir la expectativa que estos lectores tenían en relación con la literatura de viajes, lo cual permitiría el encargo de nuevos textos por parte de los periódicos. En este sentido, aunque el verdadero perfil de Ildefonso Bermejo era el de un dramaturgo, periodista y educador, en sus textos sobre viajes se retrató a sí mismo como el viajero prototípico: un aventurero atraído por el peligro que no desdeña tener que arrostrar grandes dificultades en pro del conocimiento científico, sobre todo el referente a la zoología, la botánica, la mineralogía y la antropología. Los cuatro textos estudiados explotan lo diferente, lo exótico, las otras razas: tres de ellos hablan del contacto con indios sudamericanos sin mucho trato con la civilización occidental, siendo algunos de ellos abiertamente hostiles. Desde luego, esta opción del «salvaje» como objeto principal de los escritos no es gratuita, sino que responde a la demanda del público por lo insólito y peligroso. El texto sobre Dominga Bamboyena también obedece a la misma intención de asombrar al lector español con personajes infrecuentes e inesperados. Complementariamente, la omisión de los centros urbanos europeizados en los textos de Bermejo es una decisión que también responde a los intereses de los lectores, que sienten especial atracción por lo alejado geográfica y (sobre todo) culturalmente. Ese es también el motivo de que se pase por alto la descripción de Guayaquil en la historia de Bamboyena, descripción que, por otra parte, restaría agilidad a la narración. De esta manera, al igual que otros muchos escritores de viajes, Ber-

${ }^{24}$ Como tal se presenta, por ejemplo, Augusto Jerez Perchet en las páginas de El Museo Universal (Chozas, 2014, passim). 
mejo escribe sus textos al dictado de los gustos del público, poniendo el acento, e incluso exagerando, los aspectos más atractivos para los lectores, como son las situaciones de peligro ante los «salvajes». De esta manera, la literatura de viajes de Bermejo, como es habitual en el siglo XIX, presenta una realidad sesgada que termina alimentando las expectativas y los estereotipos de los lectores. Puesto que en la biografía de Bermejo escasean las aventuras, el autor recurre pronto a la imaginación y al plagio para satisfacer la demanda de los lectores, y garantizar de esta manera su supervivencia como escritor de viajes. Tanto por este motivo como por las características formales de sus textos de viajes (predominio de lo narrativo sobre lo descriptivo, abundancia de diálogos, manejo de la intriga, narración orientada a un desenlace con mensaje moral), Bermejo se inclina hacia la literatura de ficción, hacia lo que Alburquerque (2011) llama "novela de viaje», pero no podemos dejar de considerar la recepción del público, que leyó las narraciones viajeras de Bermejo como frutos de vivencias reales, pues así quiso presentarlas el autor.

Esta impostura, más que habitual en la época, nos fuerza a repensar el papel de la literatura de viaje como fuente fidedigna de conocimiento, y nos obliga a permanecer alerta ante los discursos de los viajeros y ante las imágenes que levantan, primero, y después refuerzan, de los territorios y los pueblos de Latinoamérica, pues, como vemos en los textos de Bermejo, las descripciones y vivencias retratadas en los textos pueden reflejar ideologías muy diversas, e incluso responder a intereses meramente comerciales.

En todo caso, la figura de Ildefonso Antonio Bermejo no debería pasar a la historia de la literatura de viaje apenas como un impostor rendido a su público, pues sus tres escritos de viaje más personales («Tacuatí. Crónica americana», «Escursiones por la América del Sur. Razonamientos de un salvaje» y «La negra de Guayaquil»), obviando sus fantasías y falsedades, presentan una actitud unitaria de respeto hacia el otro excepcional en su época, siendo por lo tanto un precursor de las tendencias interculturales de nuestros días. 


\section{BIBLIOGRAFÍA}

Alburquerque García, Luis (2011): «El “relato de viajes”: hitos y formas en la evolución del género", Revista de Literatura, 145: 15-34.

Alburquerque García, Luis (2015): «Poética de la literatura de viaje», en D. Chávez y M. Urdapilleta (coords.), Cartografía de la literatura de viaje en Hispanoamérica, México: UAEM.

Chozas, Diego (2014): La literatura de viaje en El Museo Universal (1857-1869), Zaragoza: Prensas Universitarias de la Universidad de Zaragoza. Disponible en línea: https://zaguan.unizar. es/record/15781/files/tesis-2014-075.pdf (consulta en noviembre de 2019).

Bermejo, Ildefonso Antonio (1863): «Tacuatí. Crónica americana», El Museo de las Familias: 258263 y 267-269. Disponible en línea: http://hemerotecadigital.bne.es/issue.vm?id=0002591 930\&search=\&lang=es (consulta en noviembre de 2019).

Bermejo, Ildefonso Antonio (1864a): Relación esplicativa acerca de las investigaciones históricas, geográficas y estadisticas hechas en varias repúblicas de la América Meridional en el periodo de ocho años, Madrid. Disponible en línea: http://bdh-rd.bne.es/viewer.vm?id=0000114839\&page=1 (consulta en noviembre de 2019).

Bermejo, Ildefonso Antonio (1864b): «Escursiones por la América del Sur. Razonamientos de un salvaje», El Museo Universal, n. ${ }^{\circ} 18:$ 142-143. Disponible en línea: https://prensahistorica. mcu.es/es/consulta/registro.do?id=10004055950 (consulta en noviembre de 2019).

Bermejo, Ildefonso Antonio (1866a): «Constitución, usos y costumbres de los indios peguenches (Chile)", La América, n. ${ }^{\circ} 16$ (27/08/1866): 3-4. Disponible en línea: http://hemerotecadigital.bne.es/issue.vm?id=0002253753\&search=\&lang=es (consulta en noviembre de 2019).

Bermejo, Ildefonso Antonio (1866b): «La negra de Guayaquil», La América, n. ${ }^{\circ} 17$ (12-9-1866): 13-14, y n. ${ }^{\circ} 18$ (27-9-1866): 13-14. Disponible en línea: http://hemerotecadigital.bne.es/ issue.vm?id=0002253827\&search=\&lang=es y http://hemerotecadigital.bne.es/issue.vm?i $\mathrm{d}=0002253928 \&$ search=\&lang=es (consulta en noviembre de 2019).

Bermejo, Ildefonso Antonio (1873): Repúblicas Americanas. Episodios de la vida privada, politica y social en la República del Paraguay, Madrid: Imprenta de R. Labajos.

Carrizo Rueda, Sofía (1997): Poética del relato de viajes, Kassel: Reichenberger.

O'Leary, Juan E. (1953): Ildefonso Bermejo, falsario, impostor y plagiario, Asunción: Biblioteca de las FF. AA. de la Nación, vol x.

Peiró Barco, José Vicente (2000): «Manifestaciones literarias del xix en Paraguay: la revista La Aurora", Arrabal, n. ${ }^{\circ}$ 2-3, Lleida: Universidad de Lleida: 33-40.

Pérez VAlle, Raquel (2015): Literatura y periodismo en el siglo XIX: El Museo de las Familias (1843-1870), Madrid: UNED. Disponible en línea: http://e-spacio.uned.es/fez/eserv/ tesisuned:Filologia-Rperez/PEREZ_VALLE_Raquel_Tesis.pdf.

Tierno Galván, Enrique (1979): "Galdós y el episodio nacional Montes de Oca», Revista de derecho politico, n. ${ }^{\circ}$ 2: 5-30.

Worth Banner, J. (1951): «Ildefonso Antonio Bermejo, iniciador del teatro en el Paraguay», Revista Iberoamericana, vol. xvir: 97-107. 
